\title{
Interprofessional collaboration in home-based community care programs: A leadership imperative
}

\author{
Jacqueline Limoges*1, Kim Jagos ${ }^{1}$, Martin McNamara ${ }^{2}$, Ian Drennan ${ }^{1}$ \\ ${ }^{1}$ Georgian College, Barrie Campus, Canada \\ ${ }^{2}$ Georgian Bay General Hospital, Canada
}

Received: May 21, 2021

Accepted: June 10, 2021

Online Published: June 29, 2021

DOI: $10.5430 /$ jnep.v11n11p15

URL: https://doi.org/10.5430/jnep.v11n11p15

\begin{abstract}
Community Paramedic (CP) services are relatively new in home-based community care, and as these programs expand, there are additional opportunities for leadership in interprofessional and cross-sectoral collaboration. Understanding the unique contributions of each health care provider can ensure that a patient-centered approach remains forefront. This qualitative study included 33 participants representing nurses, physicians and CPs involved in home-based community care. Interviews explored attitudes, barriers and enablers to collaboration, role optimization and integration of paramedics into home-based community care and were analyzed with interpretive descriptive methods. Participants recognized the benefits of CP services and positive attitudes motivated them to engage in collaboration to support patient-centered care. Participants stated they require support and leadership to strengthen interprofessional collaboration and care coordination. Strategies such as the removal of silos, forging new networks of collaboration, interprofessional education, and changes in professional regulation for paramedics can support new roles and opportunities for nurses, paramedics and physicians in home-based community care.
\end{abstract}

Key Words: Interprofessional collaboration, Home-based community care, Health system transformation, Integration, Patientcentered care, Community paramedic

\section{INTRODUCTION}

The role of paramedics in Canada is expanding beyond traditional 911-based emergency response to provide services in home-based community care, creating new opportunities for interprofessional and cross-sectoral collaboration. Community paramedic $(\mathrm{CP})$ services vary in scope and practice from region to region, but often focus on health promotion, management of chronic illness, patient education, and interventions aimed at keeping patients in their homes and away from emergency departments. Ideally, health system transformation and the implementation of a new model of home-based community care involves role optimization, inter/intraprofessional and cross-sectoral collaboration, and removal of silos in care provision. ${ }^{[1]}$ Therefore, this study explored the attitudes, barriers, and enablers to collaborative practice between nurses, physicians and paramedics, and how the implementation of CP services influenced professional roles. Understanding the experiences and willingness of health providers to engage in role expansion, collaboration, and the dismantling of silos can guide leadership initiatives to support successful health system transformation and patient-centered care.

\section{Background}

Approximately one million Canadians receive home care each day. A recent study by the Canadian Institute of Health

*Correspondence: Jacqueline Limoges; Email: Jacqueline.Limoges@GeorgianCollege.ca; Address: Georgian College, Barrie Campus, Canada. 
Information ${ }^{[2]}$ revealed that about one in nine newly admitted long-term care residents could have remained in their homes had they received more homecare. Given the preference of most older adults to remain at home, and the challenges in long term care revealed by the COVID-19 pandemic, strengthening the homecare system is important. CP programs are developing throughout Canada to address unmet care needs. There is a leadership imperative to integrate $\mathrm{CP}$ programs into current homecare systems.

Recent studies suggest that interprofessional collaboration in home-based community care programs leads to safe and appropriate care, and positively impacts patient outcomes. ${ }^{[3-5]}$ For instance, collaboration between paramedics and nurses increased patient satisfaction, reduced emergency department visits ${ }^{[6]}$ and enabled effective health promotion and disease prevention strategies. ${ }^{[7-9]}$ Other studies reported how interprofessional collaboration and care coordination improved patient satisfaction, lowered blood pressure readings, decreased emergency (911) calls and ER visits, and improved provider job satisfaction. ${ }^{[5,10,11]}$ These and other studies $^{[12,13]}$ point to how community paramedic programs benefit patients, the health system, and health care providers and can reduce healthcare costs.

Inter and intra-professional collaboration is a complex social process that requires careful and deliberate development. ${ }^{[14-16]}$ Despite the willingness of health providers to collaborate, most do not know how to do so effectively and require education to learn this skill and about the contributions of other healthcare providers. ${ }^{[17-19]}$ Interprofessional collaboration can be difficult when professional groups create boundaries around their work to protect their domain of practice and when services begin to overlap. ${ }^{[20-22]}$ As paramedics enter into new practice areas beyond the traditional role of first responders, they are likely to both activate their own boundaries and encounter the boundaries of other professions. Leadership, policy and education can support effective inter-and intra-professional collaboration and assist professionals to work toward patient centered healthcare delivery. ${ }^{[1,15,16,23,24]}$ This research begins to address these knowledge gaps.

\section{Methods}

This study was designed using qualitative methods, which were approved by the institutional research ethics board to explore the CP program in Ontario as a case example. The design included semi-structured interviews with nurses, paramedics, physicians, and faculty who teach in CP programs (see Table 1 for sample questions). This approach allowed the examination of interprofessional collaboration in a real-world context and with people directly involved in home-based community care. The language used by informants was analyzed to identify the attitudes and social processes involved in collaboration, and role expansion in CPs in Ontario, Canada. This design assisted us to answer the following research questions:

1) What are the attitudes, perceptions, barriers and enablers of role optimization of nurses, paramedics and physicians in home-based community care?

2) What are the attitudes, perceptions, barriers and enablers of collaboration between nurses, paramedics and physicians for the provision of home-based community care?

3) What are the attitudes, perceptions, barriers and enablers of faculty as they prepare students for the new model of home-based community care?

4) What structures and competencies support the implementation of this new model of care?

Table 1. Sample interview questions

1. What is your experience with paramedics working in home
care?
2. How has your work changed since paramedics have increased
their involvement in home care?
3. What influences collaboration and interprofessional care
between nurses, physicians and paramedics in home care?
4. What initiatives (or networks) were implemented to support
collaboration between professions working in home care?
5. What additional structures and competencies are needed to
support collaboration and the integration of paramedics into
home care?

Three recruitment strategies were used to invite participants to the study. The first was through the professional networks of the four researchers. To expand the sample, the researchers contacted people known to have professional roles and responsibilities in home-based community care, then snow-ball sampling was used. After consent, semistructured interviews were conducted, audio recorded and transcribed verbatim. Each participant was assigned a code to ensure anonymity.

\subsection{Sample}

In total eight nurses, six physicians, twelve paramedics and seven faculty from Ontario were interviewed $(\mathrm{N}=33)$. The sample represented a cross-section of ages, years of experience and education (see Table 2). Six of the eight nurses worked in CP programs as nurse practitioners, nurse navigators, or managers with leadership roles. Two nurses intersected with CPs in the home at point of care. Several nurses at the management level were unaware of CP programs. All six physicians had direct involvement in overseeing CPs as either base hospital doctors, family physicians or internists. Paramedics represented the largest group in the sample, work-

ISSN 1925-4040 E-ISSN 1925-4059 
ing either in direct care or in leadership/supervisory roles. and all taught in college CP education programs.

Five faculty participants were paramedics, two were nurses

Table 2. Demographic data

\begin{tabular}{lllll}
\hline Interviews N 33 & Orientation & Age & Education & Years of experience \\
\hline Nursing $=8$ & & $<35=3$ & College $=10$ & $<5=2$ \\
Physicians $=6$ & Male $=13$ & $35-44=10$ & Undergraduate $=7$ & $6-15=6$ \\
Paramedics $=12$ & Female $=20$ & $45-54=13$ & Graduate $=10$ & $>15=25$ \\
Faculty $=7$ & & $>55=7$ & Medical degree $=6$ & \\
\hline
\end{tabular}

\subsection{Data analysis}

Investigator triangulation using interviews and analysis by an interprofessional research team supported the trustworthiness, credibility and reliability of the findings. ${ }^{[25]}$ The analysis by the interprofessional team enabled multiple perspectives within the same study to ensure disciplinary relevance. Triangulation with multiple data sources was supported through the inclusion of nurses, community paramedics and physicians in the sample which also enhanced contextual awareness. Qualitative data came from transcripts of the semi-structured interviews. Analysis was informed by Thorne's Interpretive Description which is a pragmatic method suited for research with health practice disciplines. ${ }^{[25]}$

Each member of the research team read the transcripts independently to identify themes and social processes related to interprofessional collaboration and role optimization. Coding and peer debriefing guided the comparison of memos, codes, and salient categories. ${ }^{[25]}$ Consideration was given to how the participants' experiences related to the broader context of the health system and professional regulation. Disagreements in interpretation were addressed by returning to the transcript data to ensure a reliable analysis. The research team continued this process until consensus was achieved on the findings. This rigorous process ensured that the findings from the data were interrogated and trustworthy.

\section{RESUlts}

Analysis of the interviews generated three main findings related to interprofessional collaboration in home-based CP programs. The first finding details the attitudes, barriers and enablers to collaboration between nurses, physicians and paramedics. The second finding highlights how professional roles are influenced by $\mathrm{CP}$ services and the third finding describes structures that would strengthen interprofessional collaboration between nurses, physicians and paramedics during home-based community care.

Published by Sciedu Press

\subsection{Enablers and barriers to collaboration}

\subsubsection{Positive attitudes enable collaboration}

All participants relayed a positive attitude towards collaboration. Overwhelmingly, nurses, paramedics, and physicians working in home-based community care felt CP programs enabled patients to stay in their homes longer, have a better quality of life and reduced ER visits. They indicated that the $\mathrm{CP}$ programs were innovative, delivering safe, patientcentered care. All participants had favorable attitudes towards working together to support patient-centered goals.

Nurse participants had positive attitudes towards collaboration and were willing to develop relationships with CPs. Nurse J03 mentioned: "There's enough work for everybody... we need all the players and we need all the different roles. I think it's important to look at how we mesh together to improve outcomes." However, homecare nurses experienced little interaction with CPs which was problematic given nurses' involvement in that sector.

The strongest collaborative relationships occurred between physicians and paramedics. Paramedics explained that forging and maintaining positive and trusting relationships with physicians was crucial as they require medical delegation in order to practice. As paramedic K04 stated: "When a physician puts that level of trust in you, it makes you want to do an even better job... you don't want to jeopardize the professional relationship or trust... you're nurturing a relationship... it just feels more holistic. Like full respect." These positive and productive relationships motivated paramedics to seek opportunities to expand $\mathrm{CP}$ services and forge new collaborative partnerships with physicians. Overall, the paramedics were proud of their contributions and excited by the new role they were performing in home-based community care. Likewise, physician's felt CPs were addressing unmet patient needs and helping to improve patient outcomes as illustrated by physician M01 "they could do just about anything in the community due to medical directives."

\subsubsection{Silos create barriers to collaboration}

Participants indicated that the lack of integration of CP services into the larger health system created silos, and was a 
key barrier to collaboration. CP programs operate regionally with little input from the larger health system including existing homecare structures. Physician J09 explains: "Everyone's coming in their own silos... I can see that we didn't go very far in connecting with the nurses in home care. They are not connected to us which is a shame. They should be part of the team." Participants revealed few opportunities for $\mathrm{CPs}$ and nurses to collaborate and learn from one another's expertise. As one nurse manager K08 indicated: "It would be a fluke if they [nurses] were there when the paramedic came by to assess somebody... there's just not a lot of opportunities for RNs to collaborate with paramedics". The CPs also recognized the barriers to siloed healthcare when paramedic K05 stated: "They [nurses] are not fully aware of our skill set and they're not fully aware of the programs... I find... there's still a lot of nurses that don't really understand the difference between the 911 aspect and the community aspect."

The siloed system can lead to a lack of awareness of the roles, responsibilities and skillsets of other professions, create barriers to communication and collaboration, and result in duplication and overlap in services. Participants mentioned that patients receiving both nursing and $\mathrm{CP}$ services were often confused by the role of each care provider. Moreover, documentation systems for the CPs and physicians were separate from the nurses, making it difficult to know what care was being provided to the patient. Paramedic K06 captures this sentiment well: "I'd really like to see the interprofessional aspects developed further so that we're not all working in our little silos and instead, work as a professional team, to actually look at servicing the community better." Acknowledging the barriers and enablers was helpful to participants as it provided opportunities to consider alternative strategies and identify options.

\subsection{New roles and new opportunities}

Some physician and paramedic participants used the term "physician extender" to suggest that the CP served as the eyes, ears and hands for the physician when caring for patients at home. This inferred that the paramedic was not a distinct role or profession. Nurse participants noticed this as well. For instance, nurse J05 stated: "Our CP staff are really an extension of the... doctor or the nurse practitioner... taking on that medical management role where they are able to oversee patients on behalf of the physician." Some CPs recognized that their role resembled nursing practice while others considered it to be unique and distinct: a new profession. All nurses in the study detected significant overlap between the services of community nurses and CPs. They also identified that role optimization for nurses, in light of the introduction of CP services, had not yet been explored as far as they could tell. The nurse participants acknowledged their significant expertise in leadership, patient education, chronic disease management, cultural diversity, and palliative care and how their expertise could be used to strengthen patient-centered care in $\mathrm{CP}$ through education and community programs. All participants commented on the importance of addressing the distinct and overlapping boundaries between providers to ensuring safe patient centered care and the right care, in the right place at the right time.

\subsection{Structures to support collaboration \\ 3.3.1 Interprofessional education}

Participants identified two types of interprofessional education (IPE) that could enhance collaboration. The first involves joint education with physicians, nurses and paramedics caring for the same roster of patients. Participants indicated that this would unify the health care team to deliver a common practice approach to meet patient needs. A second type of IPE is within the CP and nursing education programs. Faculty participants identified that nursing and CP knowledge overlaps and that IPE would support role clarification and collaboration. All participants stated that IPE should include a focus on leadership, interprofessional collaboration and consultation.

Faculty in this study provided examples of how this education could unfold. For instance, faculty J08 stated "If there was the opportunity to teach them [CPs] some of the leadership skills and... the inter-collaborative communication skills, conflict management skills... that would enhance the educational program." Other participants thought that nurses and paramedics could jointly learn about the relational and patient engagement strategies that are essential in home-based community care. Participants could also see how extending interprofessional education with other professions such as physiotherapy, occupational therapy and pharmacy could be beneficial.

\subsubsection{Communication systems enable collaboration}

Sharing an electronic medical record (EMR) was reported as a significant positive influence on collaboration. Some CPs shared the EMR with the physician's office, which provided quick access to information and each other. Homecare nurses did not share access to this EMR and they could see the benefits access would offer them. Physician M03 stated: "The paramedics communicate right in my EMR... the note is typically exactly what I'm looking for... the right quality, the right detail. The shared documentation enables me to keep an eye on a lot of folks." Paramedic I01 explained another benefit: "All the bloodwork, all our assessment findings, the treatment plan, our... diagnosis... is in the same EMR." The 
shared use of the EMR by the physician and CP helped both find solutions quickly, promoting a stronger collaborative relationship. When the EMR was not shared, it was considered a barrier to collaboration and communication, affecting the timeliness of patient care activities.

\section{Discussion}

The expansion of paramedics from the emergency 911 service into home-based community care in Ontario requires leaders to establish new networks of collaboration, professional boundaries, roles, and additional education and credentialing. While this study used the case of Ontario CPs, similar programs are rapidly expanding across Canada and in other countries such as the United States, United Kingdom and Australia. Our findings are important because they provide guidance to leaders to support collaboration, which is a key component to achieving the documented outcomes of CP programs. Participants in this study agreed that interprofessional collaboration would improve health system utilization and patient-centered care in community programs. The positive attitudes conveyed by participants reflect the socialization of professionals to the concept that interprofessional and cross-sectoral collaboration will lead to safe and effective patient-centered care. ${ }^{[14]}$ Many of the positive attributes described by Bookey-Bassett et al., ${ }^{[14]}$ such as shared goals, interdependence, and effective and frequent communication were noted enablers to collaboration by the CPs and physicians in this study. The antecedents identified by Bookey-Bassett such as interprofessional education, role awareness and trust between team members were also strengths identified by participants in this study. Leaders can leverage these strengths to support health system integration and collaborative relationships. ${ }^{[26,27]}$

IPE was a key structure endorsed by all participants as a way to improve collaboration, to avoid the perpetuation of misconceptions and to promote understanding of each profession. O'Meara et al. ${ }^{[28]}$ also identified how an increased awareness of the $\mathrm{CP}$ role, capabilities, and competencies could support the positive outcomes and integration of $\mathrm{CP}$ practice. The following example highlights the value of interprofessional collaboration in the planning of IPE. Nurse faculty participants identified that nurses could teach conflict resolution and leadership to paramedics. Through our investigator triangulation during data analysis, these same areas of expertise were awarded to paramedics, and it was suggested that paramedics could teach this to nurses. Leaders who understand the value of IPE in this context can use enhanced IPE strategies to support understanding of the skills and strengths in CPs and nurses, and where overlap may occur. In turn, by recognizing the distinct contributions made

Published by Sciedu Press by each profession, interprofessional consultation and crosssectoral collaboration could be strengthened to ensure the right care provider is addressing patient needs.

As an unregulated healthcare provider, Ontario paramedic practice requires oversight by a regulated health professional. Presently, legislation in Ontario only permits paramedics to accept delegation from a physician. Participants noted that this impacted the ability of paramedics to forge additional networks of collaboration, such as those with nurses. O'Meara et al. ${ }^{[28]}$ also addressed the requirement for physician oversight and how this impacted the scope of practice of CPs. Addressing regulation and professional autonomy may enable CPs to enhance their contribution to patient care and provide freedom to forge additional networks and relationships. We posit that in provinces where paramedics are regulated, interprofessional collaboration would still need to be cultivated to ensure a patient centered approach to care. Leadership is required to ensure all healthcare providers are using their full knowledge and skill and that unnecessary barriers are addressed.

To date, CPs have not fully defined their role, scope of practice, or skillset which creates challenges in describing $\mathrm{CP}$ practice, and when forging collaborations. For instance, some participants identified CPs as physician extenders, others believed they were carving out an entirely new profession and some saw significant overlap between the $\mathrm{CP}$ role and nursing practice. Once the $\mathrm{CP}$ role is further clarified, education programs can be standardized, assisting with role clarity and collaboration. ${ }^{[3]}$ Leadership is needed to support strategies for role optimization of nurses, $\mathrm{CP}$ and physicians, for new models of care, and associated policies and procedures that support collaboration.

\section{Limitations}

The CPs in our sample may have a biased view of CP practice as they chose to work in this role and because they studied in the same CP education program. The researchers had difficulty locating nurses who were aware of the $\mathrm{CP}$ program and thus this study may be missing an important perspective. There are regional differences in $\mathrm{CP}$ services and thus the experiences of the Ontario participants may not represent all areas.

\section{Conclusion}

The results of this study provide knowledge on the attitudes, barriers, and enablers to effective collaboration and role expansion of nurses, paramedics and physicians in home-based community care. At present, $\mathrm{CP}$ practice is a siloed health service, largely based on collaborative relationships between physicians and paramedics. Given the significant role and 
expertise of nurses in home-based community care, leadership can support additional networks of collaboration which could strengthen the integration and transformation of the health system to support patient-centered approaches to care. Additionally, effective teamwork and collaboration can support effective and efficient healthcare delivery. There are several opportunities to harness positive attitudes and enhance interprofessional collaboration, to optimize roles and to expand the integration of $\mathrm{CP}$ services into home-based community care. Providing interprofessional education that explores the contribution of CPs, nurses and physicians in home-based community care can support collaboration and enable stronger patient-centered care. This study can guide leadership to support health system transformation and integration. Additional research is required to measure outcomes of effective collaboration and health system transformation and to develop education programs for all health providers involved in home-based community care. Given the significant disruptions from the COVID-19 Pandemic on the health system, the timing for health system innovation that includes stronger collaboration is good. Theories of the professions and professionalization in the era of inter-professionalism are required to explore these complex social processes.

\section{ACKNOWLEDGEMENTS}

Muskaan Karwal Research Assistant; Georgian College for seed funding to support the research

\section{CONFLICTS OF INTEREST DisClOSURE}

The authors declare that there is no conflict of interest.

\section{REFERENCES}

[1] Nelson S, Turnbull J, Bainbridge L, et al. Optimizing Scopes of Practice: New Models for a New Health Care System. Ottawa, Ontario: Canadian Academy of Health Sciences; 2014 p. 1-14.

[2] 1 in 9 new long-term care residents potentially could have been cared for at home [Internet]. CIHI. [cited 2021Feb 25]. Available from: https://www.cihi.ca/en/1-in-9-new-long-term-c are-residents-potentially-could-have-been-cared- $f$ or-at-home

[3] Van Vuuren J, Thomas B, Agarwal G, et al. Reshaping healthcare delivery for elderly patients: the role of community paramedicine; a systematic review. BMC Health Serv Res. 2021; 21(1). PMid:33407406 https://doi.org/10.1186/s12913-020-06037-0

[4] Thurman WA, Moczygemba LR, Tormey K, et al. A scoping review of community paramedicine: evidence and implications for interprofessional practice. J Interprof Care. 2020; 35(2): 22939. PMid:32233898 https://doi.org/10.1080/13561820.2 020.1732312

[5] Agarwal G, Angeles R, Pirrie M, et al. Effectiveness of a community paramedic-led health assessment and education initiative in a seniors' residence building: the Community Health Assessment Program through Emergency Medical Services (CHAP-EMS). BMC Emerg Med. 2016; 17(1). PMid:28274221 https://doi.org/10.1186/ s12873-017-0119-4

[6] Kant RE, Vejar M, Parnes B, et al. Outcomes and provider perspectives on geriatric care by a nurse practitioner-led community paramedicine program. Geriatr Nurs. 2018; 39(5): 574-9. PMid:29731391 https://doi.org/10.1016/j.gerinurse. 20 18.04 .003

[7] Boykin A, Wright D, Stevens L, et al. Interprofessional care collaboration for patients with heart failure. Am J Health Syst Pharm. 2018; 75(1). PMid:29273612 https://doi.org/10.2146/ajhp 160318

[8] Dainty KN, Seaton MB, Drennan IR, et al. Home Visit-Based Community Paramedicine and Its Potential Role in Improving PatientCentered Primary Care: A Grounded Theory Study and Framework. Health Serv Res. 2018; 53(5): 3455-70. PMid:29542111 https://doi.org/10.1111/1475-6773.12855
[9] O'Meara P, Duthie S. Paramedicine in Australia and New Zealand: A comparative overview. Aust J Rural Health. 2018; 26(5): 363-8. PMid:30303284 https://doi.org/10.1111/ajr.12464

[10] Whalen S, Goldstein J, Urquhart R, et al. The novel role of paramedics in collaborative emergency centres aligns with their professional identity: A qualitative analysis. CJEM. 2018; 20(4): 518-22. PMid:30033895 https://doi.org/10.1017/cem. 2018.401

[11] Ruest MR, Ashton CW, Millar J. Community Health Evaluations Completed Using Paramedic Service (CHECUPS): Design and Implementation of a New Community-Based Health Program. JHHSA. 2017; 40: 186-218.

[12] Agarwal G, Pirrie M, Angeles R, et al. Cost-effectiveness analysis of a community paramedicine programme for low-income seniors living in subsidised housing: the community paramedicine at clinic programme (CP@clinic). BMJ Open. 2020; 10(10). PMid:33109643 https://doi.org/10.1136/bmjopen-2020-037386

[13] Xie F, Yan J, Agarwal G, et al. Economic Analysis of Mobile Integrated Health Care Delivered by Emergency Medical Services Paramedic Teams. JAMA Netw Open. 2021; 4(2). PMid:33625510 https://doi.org/10.1001/jamanetworkopen.2021.0055

[14] Bookey-Bassett S, Markle-Reid M, Mckey CA, et al. Understanding interprofessional collaboration in the context of chronic disease management for older adults living in communities: a concept analysis. J Adv Nurs. 2016; 73(1): 71-84. PMid:27681818 https://doi.org/10.1111/jan.13162

[15] Limoges J, Jagos K. The influences of nursing education on the socialization and professional working relationships of Canadian practical and degree nursing students: A critical analysis. Nurse Educ Today. 2015; 35(10): 1023-7. PMid:26260523 https ://doi .org/ $10.1016 / j$.nedt .2015 .07 .018

[16] Limoges J, Jagos K, Lankshear S, et al. Getting to the root of it: How do faculty address professional boundaries, role expansion, and intra-professional collaboration? J Nurs Educ and Prac. 2016; 8(9): 113-121. https://doi.org/10.5430/jnep.v8n9p113

[17] A National Interprofessional Competence Framework [Internet]. Canadian Interprofessional Health Collaborative. 2010 [cited 2021]. Available from: http://www.cihc.ca/files/CIHC_IPCompete ncies_Feb1210.pdf 
[18] Moore J, Prentice D, Salfi J. A mixed-methods pilot study of the factors that influence collaboration among registered nurses and registered practical nurses in acute care. Nurs Res Pract. 2017; 5(4): 1.

[19] Nelson S, Tassone M, Hodges BD. Creating the health care team of the future: the Toronto model for interprofessional education and practice. Ithaca, New York: ILR Press, an imprint of Cornell University Press; 2016.

[20] Farahani MA, Mahboube L, Talebi E, et al. Comparing the attitude of doctors and nurses toward factor of collaborative relationships. J Family Med Prim Care. 2019; 8(10): 3263. PMid:31742153 https://doi.org/10.4103/jfmpc.jfmpc_596_19

[21] Witz A. Patriarchy and Professions: The Gendered Politics of Occupational Closure. Sociology. 1990; 24(4): 675-90. https: //doi.org/10.1177/0038038590024004007

[22] Witz A. Professions and patriarchy. London, England: Routledge; 1992. https://doi.org/10.2307/2075792

[23] Bainbridge L, Wood VI. The power of prepositions: Learning with, from and about others in the context of interprofessional education. J Interprof Care. 2012; 26(6): 452-8. PMid:22897364 https://doi.org/10.3109/13561820.2012.715605

[24] Baker L, Egan-Lee E, Martimianakis MA, et al. Relationships of power: implications for interprofessional education. Journal Interprof Care. 2010; 25(2): 98-104.

[25] Thorne SE. Interpretive description: qualitative research for applied practice. New York, NY: Routledge; 2017.

[26] Folkman AK, Tveit B, Sverdrup S. Leadership in interprofessional collaboration in health care. J Multidiscip Healthc. 2019; 12: 97-107. PMid:30787619 https://doi.org/10.2147/JMDH.S189199

[27] Whalen S, Goldstein J, Urquhart R, et al. The novel role of paramedics in collaborative emergency centres aligns with their professional identity: A qualitative analysis. CJEM. 2018; 20(4): 518-22. PMid:30033895 https://doi.org/10.1017/cem.2018.401

[28] O'Meara P, Stirling C, Ruest M, et al. Community paramedicine model of care: an observational, ethnographic case study. BMC Health Serv Res. 2016; 16(1). PMid:26842850 https ://doi .org/ $10.1186 / \mathrm{s} 12913-016-1282-0$ 